\title{
Speech-Language Pathologists' Perceptions of the Common Core State Standards: A Multi-State Study
}

\author{
Nicole Ariza*, Patrick R. Walden \\ Department of Communication Sciences and Disorders, St. John's University, Jamaica, NY \\ Student:nicole.ariza11@stjobns.edu* \\ Mentor:waldenp@stjohns.edu
}

\begin{abstract}
This study investigated the Common Core State Standards (CCSS) from the perspective of Speech-Language Pathologists (SLPs) providing speech and language services to students with communicative disorders in schools. An invitation to participate in an anonymous, online questionnaire with both closed- and open-ended questions was posted to three online communities comprised of SLPs working in schools across the United States of America (U.S.). Eighty-seven SLPs working in states using the CCSS completed the survey. The survey focused on four primary areas - the perceived impact of the CCSS on service delivery, student outcomes, professional workload and continuing professional education. Participants reported consistent incorporation of standards into services, but varied methods of implementation, primarily unchanged student outcomes, increased professional workload and a need for additional training. Overall, the CCSS' intent to create consistent goals may not be accomplished due to variability in approaches in implementation of the standards. Additionally, more resources and trainings for SLPs are needed to fully implement the CCSS into speech-language intervention in the schools.
\end{abstract}

\section{KEYWORDS}

Common Core State Standards; School-Based Services; School-Based Issues; Speech-Language Pathology; Service Delivery; Student Outcomes; Professional Workload; Continuing Professional Education

\section{INTRODUCTION}

The Common Core State Standards (CCSS) are the current academic standards for mathematics and English language arts/literacy (ELA) created by the National Governors Association (NGA) and the Council of Chief State School Officers (CCSSO) in the United States of America (U.S.). The standards are not a curriculum, but instead provide benchmarks for what students at each grade level should know by the end of a school-year, all while ensuring college and career readiness among students. ${ }^{1}$ Staskowski reported: "The CCSS are intended to update the way schools educate and the way students learn and to ultimately prepare the nation's next generation for the global workplace" (p.95-96). ${ }^{2}$ While the standards are uniform across all states, implementation methods are decided at the state and local level, as are the instructional materials used. ${ }^{3}$ The adoption of the standards is completely voluntary, however, there are financial incentives to encourage states to implement the standards. For example, states interested in Federal "Race to the Top" funds (financial incentive from the U.S. government) must adopt the CCSS to be considered eligible. ${ }^{4}$ The CCSS have been adopted by 42 U.S. States, the District of Columbia, four U.S. territories and the U.S. Department of Defense Education Activity. ${ }^{1}$

\section{Education Standards Movement}

The education standards movement is the nation-wide interest in creating more challenging standards for students in academia and is rooted in the concern that the U.S. is not an academic competitor when compared to other countries. ${ }^{3}$ The timeline of events within the movement began in 1989 when an educational summit was held under the leadership of George H.W. Bush and the nation's governors to set state-level standards for mathematics, language arts and science. In 2002, The No Child Left Behind (NCLB) Act placed a new emphasis on educator accountability through the use of state assessments used for school accreditation as well as the sanctioning of "low-performance" schools. Concerns for state-to-state standard variability began to emerge as attention was drawn to students who completed their schooling in different U.S. States, becoming prone to a possible achievement gap as they missed or repeated content. ${ }^{3}$ In 2009, the development of the CCSS began in order to create consistent standards in English/language arts and mathematics across all states. The standards were created with input from content experts, teachers, parents, school chiefs and administrators and are "research-and-evidence-based". ${ }^{1}$ In 2010 , the NGA and CCSSO released the CCSS and in 2014, individual state assessments were replaced by the Partnership for Assessment of Readiness for College and Careers (PARCC) and the Smarter Balanced Assessment Consortium (SBAC), used across states who have adopted the standards. ${ }^{3}$ 


\section{Support \& Criticism for the CCSS}

The CCSS have garnered both positive attention and heavy criticism. ${ }^{5}$ Some supporters of the CCSS believe the standards are the solution to a broken education system. The Program for International Student Assessment (PISA), which measures the performance of 15 year-olds' reading, mathematics and science across the globe indicated that U.S. student performance, which ranked $31^{\text {st }}$ in math and $17^{\text {th }}$ in reading literacy, was below China, Finland, Singapore, Hong Kong, South Korea, Canada and Japan. ${ }^{2}$ Other supporters explain that while the U.S. has high unemployment rates, there is a shortage of high-skilled workers, creating a "skills gap" in the areas of leadership, adaptability, literacy and numeracy, creativity and communication. These skills have not been a substantial focus in previous educational systems. ${ }^{2}$ Many CCSS supporters also believe that the standards promote equality. In the past, students who struggled in their early years of school due to disabilities or language differences were taught less course material and fell further behind as they moved up grade levels. New educational standards found in the CCSS, however, promote "higher-quality education for all students, regardless of race, economic status, or disability" (p. 97). ${ }^{2}$

Most who argue against the CCSS agree that past standards have inadequately met the needs of students, but explain that the new standards are not a satisfactory solution to the deep-rooted problems within the U.S. educational system. One prominent argument against the CCSS is the ineffective implementation of the standards. The implementation methods used have been inconsistent across states and districts, and many schools are lacking in professional development efforts, leaving teachers unprepared to develop aligned curriculums. ${ }^{5}$ Furthermore, while supporters of the CCSS highlight the opportunity for equality, those opposed argue that the standards do not solve the problems posed by factors such as "poverty, isolation and social inequity" that are present before classroom learning begins. ${ }^{6}$ Because diverse students learn and develop at different rates, they should not necessarily be held to the same standards. Other arguments against the CCSS include the inappropriate difficulty level of the assessments, failure of standardization efforts in other countries and conflicts of interest related to much of the CCSS cited research. 5,6

\section{School-Based SLPs \&Incorporation of the CCSS}

Speech-Language Pathologists (SLPs) are licensed professionals who prevent, assess, and treat disorders of communication and swallowing. SLPs work in both educational and healthcare settings with the primary goal to improve the communication (speech/language/hearing) competence of students and patients. According to the American Speech-Language-Hearing Association, SLPs play a crucial role in implementing the CCSS for students with communication disorders. ${ }^{7}$ SLPs can provide input on curriculum and functional goals while working with an education team to benefit each individual child. To effectively provide this input, SLPs should be familiar with the standards, know the curriculum being used, understand what is expected of typically developing students in relation to listening, speaking, reading and writing, collaborate with other school professionals and understand the needs of diverse students.

Students with disabilities are protected under the Individuals with Disabilities Education Act 2014 (IDEA), which ensures the right to a "free and appropriate education". Of special interest to the SLP working with the CCSS is the Application to Students with Disabilities document, which explains how the CCSS should be applied to students with disabilities. The document states that students with disabilities should be "challenged to excel within the general curriculum and be prepared for success in their postschool lives, including college and/or careers". ${ }^{8}$

Given the developing role of the SLP in providing services consistent with the CCSS, it is vital to understand how SLPs have been prepared to meet this challenge. Therefore, the purpose of this survey study was to learn more about how SLPs working with students in public schools perceive the CCSS. The research asked "How do SLPs working in schools perceive the CCSS' impact on:

1. service delivery

2. student outcomes

3. professional workload

4. continuing professional education?"

\section{METHODS AND PROCEDURES}

\section{Procedures}

An invitation to take an anonymous, online survey and a direct link to the survey were posted on the American Speech-LanguageHearing Association's (the accrediting body for SLPs in the U.S.) Special Interest Group 1: Language Learning and Education online community, the Special Interest Group 16: School-Based Issues online community as well as the SLP schools online community. One subsequent reminder invitation was posted on these communities. St. John's University IRB approval was granted prior to administration of the survey. 


\section{Participants}

Table 1 presents a breakdown of the backgrounds of the participants. The 106 participants were school-based Speech-Language Pathologists across the United States. Of the 106 participants, a total of 87 participants indicated they worked in a Common Core State and completed the survey. Most (83; 89.25\%) participants worked in traditional public schools. Likewise, most $(69 ; 79.31 \%)$ reported being over 40 years of age, and the majority $(67 ; 77.91) \%$ indicated having worked in schools for over 10 years. All participants of the survey were female, which is typical of the profession. ${ }^{9}$

\begin{tabular}{|c|c|c|}
\hline $\begin{array}{l}\text { Professional experience, school logistics } \\
\text { and demographics }\end{array}$ & Number of respondents & Percentage of respondents \\
\hline $\begin{array}{l}\text { Type of School } \\
\text { Traditional public school } \\
\text { Public charter school } \\
\text { Private school } \\
\text { Special Education school }\end{array}$ & $\begin{array}{l}83 \\
2 \\
1 \\
7 \\
\end{array}$ & $\begin{array}{l}89.25 \% \\
2.15 \% \\
1.08 \% \\
7.53 \% \\
\end{array}$ \\
\hline $\begin{array}{l}\text { Employment Location } \\
\text { Urban } \\
\text { Suburban } \\
\text { Rural }\end{array}$ & $\begin{array}{l}19 \\
54 \\
13\end{array}$ & $\begin{array}{l}22.09 \% \\
62.79 \% \\
15.12 \%\end{array}$ \\
\hline $\begin{array}{l}\text { Age } \\
25 \text { and under } \\
26-40 \\
41-55 \\
56 \text { or older }\end{array}$ & $\begin{array}{l}0 \\
18 \\
35 \\
34\end{array}$ & $\begin{array}{l}0.00 \% \\
20.69 \% \\
40.23 \% \\
39.08 \%\end{array}$ \\
\hline $\begin{array}{l}\text { Gender } \\
\text { Male } \\
\text { Female }\end{array}$ & $\begin{array}{l}0 \\
87\end{array}$ & $\begin{array}{l}0.00 \% \\
100 \%\end{array}$ \\
\hline $\begin{array}{l}\text { Degree Level } \\
\text { Bachelor's } \\
\text { Master's } \\
\text { Doctoral }\end{array}$ & $\begin{array}{l}0 \\
82 \\
4\end{array}$ & $\begin{array}{l}0.00 \% \\
95.35 \% \\
4.65 \%\end{array}$ \\
\hline $\begin{array}{l}\text { Grade Level Worked With } \\
\text { K-2 } \\
3-5 \\
6-8 \\
9-12\end{array}$ & $\begin{array}{l}68 \\
65 \\
42 \\
27\end{array}$ & $\begin{array}{l}79.07 \% \\
75.58 \% \\
48.84 \% \\
31.40 \% \\
\text { *multiple professions selected by each } \\
\text { participant }\end{array}$ \\
\hline $\begin{array}{l}\text { Years of Clinical Experience in a School } \\
1-2 \\
3-10 \\
11-18 \\
19-26 \\
26+ \\
\text { CF-Year }\end{array}$ & $\begin{array}{l}6 \\
13 \\
17 \\
17 \\
33 \\
0\end{array}$ & $\begin{array}{l}6.98 \% \\
15.12 \% \\
19.77 \% \\
19.77 \% \\
38.37 \% \\
0.00 \%\end{array}$ \\
\hline
\end{tabular}

Table 1. Participant Demographics.

Note: Some participants reported working in more than one setting creating results above 100\%.

\section{Instruments}

The 58 question online survey was made using SoGoSurvey (bttp:// wmw.sogosurvey.com). The five-part survey consisted of both open and closed-ended questions. The questions were based on position statements from the American Speech-Language-Hearing Association (accrediting body for SLPs) and overall implications of the Common Core State Standards. ${ }^{7}$ The first section was a series of questions pertaining to the respondent and workplace demographics. Responses can be seen in Table 1 . The second section focused on service delivery. SLPs were primarily asked questions regarding how they aligned standards with therapy and how they collaborated with teachers. They were also asked to rate the difficulty of both general and specific aspects of the CCSS. The questions in the third section were based on professional workload. Participants were asked to compare size of therapy groups, the number of referrals and clients, types of cases and changes in workload. The fourth section pertained to student outcomes. Questions focused on completion of Individualized Education Plan (IEP) goals, language learning-impaired students compared to their same-aged peers, motivation of children in therapy, and perceived mastery of standards. The final section centered on continuing professional education for which SLPs answered questions on training, time dedicated to preparation for therapy and overall familiarity with the CCSS. 


\section{Data Analysis}

Participant responses for most survey items were coded according to the level of agreement, frequency of occurrence, or specific categories indicated for statements concerning the CCSS and service delivery, workload, student outcomes, and continuing education. Results for these items were interpreted using descriptive statistics, specifically, percent participants reporting at each level of agreement, frequency of occurrence, or specific category chosen.

The participants also answered open-ended questions regarding each survey area. The resultant textual data underwent thematic analysis. ${ }^{10}$ Each participant response to each open-ended question was coded for its meaning(s). Coding and thematic analysis were facilitated through use of Atlas. Ti $7.5^{\mathrm{TM}}$ software package. Codes from each segment were compared to all other segments to determine suitability and to determine if new codes appeared from the data. New codes were added as necessary. After all segments were coded, codes were collapsed into themes or "similar codes aggregated together to form a major idea in the database" (p. 239). ${ }^{10}$

\section{Authenticity and Dependability of Findings}

Authenticity was achieved through the thick, rich descriptions that were used to support the reported themes. ${ }^{11}$ Descriptions, or quotes, from participants were removed due to space limitations. Reliability was conceived as the stability of findings (codes and themes) across researchers. ${ }^{11}$ To increase the dependability of the findings, both authors reviewed all codes and themes, and consensus for each was reached. Both authenticity and consensus were achieved through hours of face-to-face data review and discussion.

\section{RESULTS}

An image of the results of this study is found in Figure 1. Specifics to each area depicted in the figure follow in narrative form. Tables of extracted codes and code descriptions are presented throughout associated sections.
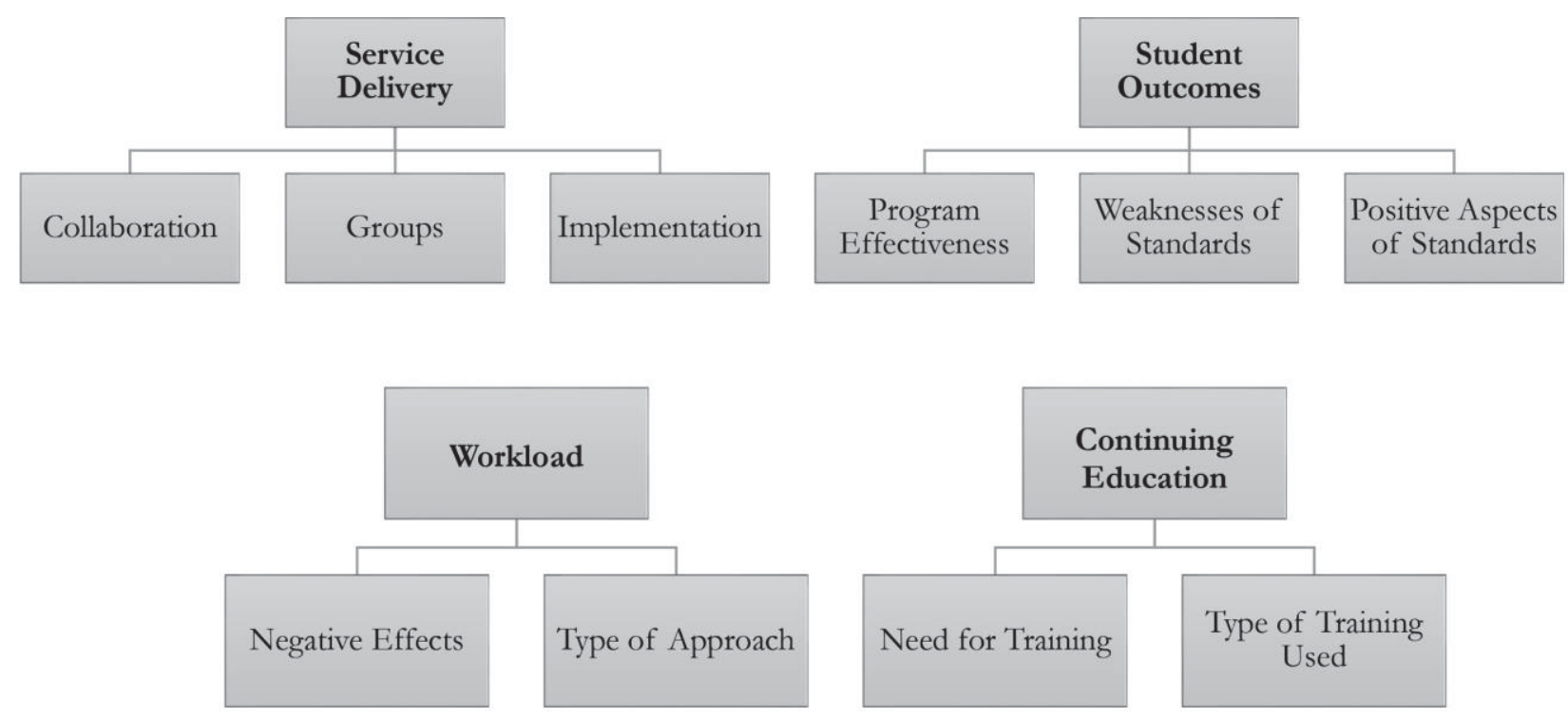

Figure 1. Survey Overview.

\section{Service Delivery}

Participant responses regarding the CCSS' effect on delivery of speech-language-hearing services fell into one of four categories: overall service delivery, collaboration, groups, and implementation. Interprofessional practice in the form of SLP-teacher collaboration was the most cited change in service delivery as a result of the CCSS. Characteristics of therapy groups were reported to be largely unchanged as a result of the CCSS (although individual report varied). Further, respondents reported that the implementation of therapy plans was affected by CCSS. Details of each of these follow. 
Regarding overall service delivery, 86.05\% (74/86) reported incorporating the CCSS into therapy in some or almost all sessions. A total of $44.83 \%(39 / 87)$ of participants indicated that developing a treatment plan that aligns with CCSS was easy or somewhat easy, and a total of $58.14 \%$ (50/86) of participants indicated that the CCSS slightly or moderately helped facilitate the generalization of skills focused on in therapy. When asked to compare time spent on the counseling aspect of therapy before and after implementation of the CCSS, 56.63\% (47/83) indicated a small amount of time spent before implementation, while 60.98\% (50/82) indicated a small amount of time spent after implementation. When asked about the helpfulness of the CCSS Application to Students with Disabilities document, 39.76\% (33/83) indicated that they were not familiar with the document, while 32.53\% $(27 / 83)$ indicated that the document was somewhat helpful.

On a scale of 0 to 5, 0 being not met and 5 being completely met, participants were asked to rate which resources needed for service delivery were provided. Time to reach goals before CCSS assessments were rated by 49.38\% (40/81) as 2 or 3. Sufficient time in therapy was rated by $50 \%(41 / 82)$ as 2 or 3 . Sufficient class time was rated by $49.38 \%(40 / 81)$ as 2 or 3 . Sufficient time for generalization of topics from therapy was rated by $55.70 \%(44 / 79)$ as 2 or 3 . Instructional supports for learning was rated by $62.96 \%(51 / 81)$ as 2 or 3 . Instructional accommodations were rated by $44.44 \%(36 / 81)$ as 4 or 5 and $44.44 \%(36 / 81)$ as 2 or 3 . Assistive technology devices/services were rated by $48.15 \%(39 / 81)$ as 2 or 3 .

\section{Collaboration}

Participants were asked to select the professions they collaborated with within the last school year (multiple professions selected by each participant). Of the 85 participants who responded, 92.94\% (79/85) selected School Psychologist, 91.76\% (78/85) selected another SLP, 87.06\% (74/85) selected School Occupational Therapist, 62.35\% (53/85) selected other professional, 57.65\% (49/85) selected School Social Worker and 54.12\% (46/85) selected School Physical Therapist. Participants were also asked about their collaborations with teachers, and 64.29\% (54/84) reported the frequency of collaborating as very or extremely often. In addition, $57.83 \%$ (48/83) indicated that their collaboration with teachers was slightly to moderately difficult and $59.76 \%$ (49/82) indicated that working with teachers to design lesson plans was slightly to moderately difficult. Finally, 53.66\% (44/82) of participants rated their overall experience collaborating with teachers as an average experience.

\begin{tabular}{|c|c|}
\hline $\begin{array}{l}\text { Collaboration-related segments } \\
\qquad(62 \text { segments total) }\end{array}$ & Description \\
\hline $\begin{array}{l}\text { Building rapport with the classroom teacher } \\
\text { ( } 25 / 62 \text { collaboration-related segments) }\end{array}$ & $\begin{array}{l}\text { Collaborative success dependent on the development of respect and friendship with classroom } \\
\text { teachers. } \\
\text { Note: Of the } 25 \text { segments assigned in this category, reference was made to supporting or } \\
\text { befriending teachers }(13 / 25) \text {, initiating collaboration with one teacher at a time }(8 / 25) \text {, and } \\
\text { explaining the professional role of an SLP }(4 / 25) \text {. }\end{array}$ \\
\hline $\begin{array}{l}\text { Adapting to teacher's lesson plans }(10 / 62 \\
\text { collaboration-related segments) }\end{array}$ & SLP works around the teacher's set lesson plans and curriculum. \\
\hline $\begin{array}{l}\text { Creating an agreed upon form of } \\
\text { communication }(7 / 62 \text { collaboration-related } \\
\text { segments) }\end{array}$ & $\begin{array}{l}\text { SLPs and teachers decide on how they will keep each other up-to-date on lesson plans and student } \\
\text { progress. }\end{array}$ \\
\hline $\begin{array}{l}\text { Collaboration as the key factor to students' } \\
\text { success }(6 / 62 \text { collaboration-related segments) }\end{array}$ & $\begin{array}{l}\text { Collaboration is the most effective way to aid in the success of students with communication } \\
\text { disorders receiving speech and language services. }\end{array}$ \\
\hline $\begin{array}{l}\text { Offering suggestions to teachers }(4 / 62 \\
\text { collaboration-related segments) }\end{array}$ & $\begin{array}{l}\text { SLPs offer suggestions to teachers regarding how they can help students with communication } \\
\text { disorders. }\end{array}$ \\
\hline $\begin{array}{l}\text { Importance of classroom observations }(4 / 62 \\
\text { collaboration-related segments) }\end{array}$ & Time spent observing students in the classroom important for collaboration. \\
\hline $\begin{array}{l}\text { Push-in as a service delivery model }(3 / 62 \\
\text { collaboration-related segments) }\end{array}$ & Preference to keep students with communication disorders in the classroom. \\
\hline $\begin{array}{l}\text { No difficulty collaborating ( } 2 / 62 \text { collaboration- } \\
\text { related segments) }\end{array}$ & Ease of use of collaboration model in service delivery. \\
\hline $\begin{array}{l}\text { Success of collaboration contingent on } \\
\text { teachers' willingness to collaborate }(1 / 62 \\
\text { collaboration-related segments) }\end{array}$ & Collaboration outcome dependent on teacher's willingness to work with the SLP. \\
\hline
\end{tabular}

Table 2. Collaboration-related segments.

Sixty-two participant open-ended responses were coded as statements referring to collaboration with teachers. These fell into nine categories: building rapport with the classroom teachers (25/62), adapting to the teacher's lesson plans (10/62), creating an agreed upon form of communication (7/62), collaboration as the key factor to students' success $(6 / 62)$, offering suggestions to teachers (4/62), importance of classroom observations (4/62), push-in as a service delivery model (3/62), no difficulty collaborating (2/62) and success of collaboration contingent on teachers' willingness to collaborate (1/62). 
Building rapport with the classroom teacher (25/62 collaboration-related segments) was assigned to responses that indicated that collaborative success was dependent on the development of respect and friendship with the teachers. Of the 25 segments assigned in this category, reference was made to supporting or befriending teachers $(13 / 25)$, initiating collaboration with one teacher at a time (8/25), and explaining the professional role of an SLP (4/25). Adapting to the teacher's lesson plans (10/62 collaborationrelated segments) referred to participant responses that suggested the SLP should work around the teacher's set lesson plans and curriculum. Creating an agreed upon form of communication (7/62 collaboration-related segments) referred to responses where the participant explained that SLPs and teachers should decide on how they will keep each other up-to-date on lesson plans and student progress. Collaboration as the key factor to students' success (6/62 collaboration-related segments) referred to responses that suggested that collaboration was the most effective way to aid in the success of students with communication disorders receiving speech and language services. Offering suggestions to teachers (4/62 collaboration-related segments) referred to participants who made suggestions to teachers regarding how they can help the students with communication disorders. The importance of classroom observations (4/62 collaboration-related codes) code was assigned to segments that suggested time spent observing students in the classroom was important for collaboration. Push-in as a service delivery model (3/62

collaboration-related codes) was assigned to responses that indicated a preference to keep students with communication disorders in the classroom. No difficulty collaborating (2/62 collaboration-related codes) referred to responses that indicated an ease of use of collaboration in service delivery. Success of collaboration contingent on teachers' willingness to collaborate $(1 / 62$

collaboration-related segments) was the code assigned to participants who suggested collaboration is only possible if the teacher is open to working with the SLP.

Groups

When asked about the number of students per group before implementation of the CCSS, 85.71\% (72/84) reported small or moderate sized groups. When asked about the number of students per group after implementation of the CCSS, 78.57\% (66/84) reported small or moderate sized groups (a decrease of $8.33 \%$ after implementation of the CCSS). When asked about the number of group sessions before the implementation of the CCSS, 82.14\% (69/84) reported a moderate or large number of sessions. When asked about the number of group sessions after the implementation of the CCSS, 89.29\% (75/84) reported a moderate or large number of sessions (an increase of $8.7 \%$ after implementation of CCSS).

\begin{tabular}{|l|l|}
\hline \multicolumn{1}{|c|}{$\begin{array}{c}\text { Group-related segments } \\
\text { (12 segments total) }\end{array}$} & Description \\
\hline $\begin{array}{l}\text { Larger group size (8/12 group-related } \\
\text { segments) } \\
\text { *part of group size }(9 / 12) \text { category }\end{array}$ & Increase of group therapy size after the implementation of the CCSS. \\
\hline $\begin{array}{l}\text { Unchanged group size (1/12 group- } \\
\text { related segments) } \\
\text { *part of group size }(9 / 12) \text { category }\end{array}$ & Unchanged group therapy size after the implementation of the CCSS. \\
\hline $\begin{array}{l}\text { Group diversity (3/12 group-related } \\
\text { segments) }\end{array}$ & Groups consisted of students with communication disorders with disparate therapy needs. \\
\hline
\end{tabular}

Table 3. Group-related segments.

Twelve participant open-ended responses were coded as statements regarding characteristics of group sessions after the implementation of the CCSS. These fell into two broad categories: group size (9/12) and group diversity (3/12).

Group size consisted of larger group size (8/12) and unchanged group size (1/12). Larger group size (8/12 group-related segments) was the code assigned to participants who indicated that the size of their group therapy sessions increased after the implementation of the CCSS. Unchanged group size (1/12 group-related segments) was the code assigned to participants who believed group therapy size remained unchanged after CCSS implementation. Group diversity (3/12 group-related segments) was assigned to responses in which SLPs reported groups consisting of students with communication disorders with disparate therapy needs (questionable grouping of students). 


\section{Implementation}

\begin{tabular}{|l|l|}
\hline \multicolumn{1}{|c|}{$\begin{array}{c}\text { Implementation-related segments } \\
\text { (175 segments total) }\end{array}$} & \multicolumn{1}{c|}{ Description } \\
\hline $\begin{array}{l}\text { Reference to standards (83/175 } \\
\text { implementation-related segments) }\end{array}$ & $\begin{array}{l}\text { Speech and language goals included use of Common Core standards. } \\
\text { Note: Of the } 83 \text { total codes in the reference to standards category, specific mention was made to } \\
\text { reference to specific standards (17/83), indirect application of standards into therapy (10/83), and } \\
\text { direct application of standards into therapy (6/83). }\end{array}$ \\
\hline $\begin{array}{l}\text { Difficulty incorporating standards into } \\
\text { therapy (24/175 implementation-related } \\
\text { segments) }\end{array}$ & Difficulty aligning standards to speech and language therapy goals. \\
\hline $\begin{array}{l}\text { Compromised service (23/175 } \\
\text { implementation-related segments) }\end{array}$ & $\begin{array}{l}\text { Decline of effective speech and language services due to demands related to incorporation of the } \\
\text { CCSS. }\end{array}$ \\
\hline $\begin{array}{l}\text { Focus on functional goals (13/175 } \\
\text { implementation-related segments) }\end{array}$ & Focus on foundational skills as opposed to Common Core standards. \\
\hline $\begin{array}{l}\text { Reference to curricular material (12/175 } \\
\text { implementation-related segments) }\end{array}$ & Speech and language goals centered on teacher's curricular material. \\
\hline $\begin{array}{l}\text { Need for prealigned therapy goals } \\
\text { (7/175 implementation-related } \\
\text { segments) }\end{array}$ & $\begin{array}{l}\text { Need for pre-made therapy goals that align with standards to adequately implement the CCSS into } \\
\text { speech and language services. }\end{array}$ \\
\hline $\begin{array}{l}\text { Implementation problems (6/175 } \\
\text { implementation-related segments) }\end{array}$ & Issues related to implementation of CCSS. \\
\hline $\begin{array}{l}\text { Need for administrative support (6/175 } \\
\text { implementation-related segments) }\end{array}$ & $\begin{array}{l}\text { Administration involvement needed to adequately implement the CCSS into speech and language } \\
\text { services. }\end{array}$ \\
\hline $\begin{array}{l}\text { No incorporation of the CCSS (1/175 } \\
\text { implementation-related segments) }\end{array}$ & No use of CCSS in speech and language services. \\
\hline
\end{tabular}

Table 4. Implementation-related segments.

One hundred seventy-five participant open-ended responses were coded as statements regarding the implementation of the CCSS (no forced choice items on survey). These fell into nine categories: reference to standards (83/175), difficulty incorporating standards into therapy (24/175), compromised service (23/175), focus on functional goals (13/175), reference to curricular material (12/175), need for prealigned therapy goals ( $7 / 175)$, implementation problems (6/175), need for administrative support (6/175), and no incorporation of the CCSS (1/175).

The reference to standards (83/175 implementation-related segments) category referred to participants who included use of the Common Core standards into speech and language services at some capacity. The 83 segments assigned to the reference to standards included reference to specific standards (17/83), indirect application of standards into therapy (10/83), and direct application of standards into therapy (6/83). The difficulty incorporating standards into therapy (24/175 implementation-related segments) was assigned to participant responses that expressed difficulty in aligning standards with therapy goals. Compromised service (23/175 implementation-related segments) was assigned to responses that indicated a decrease in effective speech and language services due to demands related to incorporation of the CCSS. Focus on functional goals (13/175 implementationrelated segments) referred to participants who indicated a focus on foundational skills as opposed to standards. The reference to curricular material (12/175 implementation-related segments) category was assigned to responses where participants explained basing speech and language services off of teacher's curricular material. Need for prealigned therapy goals ( $7 / 175$ implementationrelated segments) was assigned to participant responses that expressed a need for pre-made therapy goals and standard alignment to adequately implement the CCSS into speech and language services. Implementation problems (6/175 implementation-related segments) referred to problems in the implementation of the CCSS. Need for administrative support (6/175 implementationrelated segments) arose from participant responses that expressed a need for administration's involvement to adequately implement the CCSS into speech and language services. No incorporation of the CCSS (1/175 implementation-related segments) referred to one participant who did not use the CCSS in speech and language services.

\section{Student Outcomes}

Participants' responses fell into one of three categories related to student outcomes. Participants reported data specific to overall program and therapy effectiveness, weaknesses of the CCSS as well as positive aspects of the CCSS. Responses indicated that student outcomes remained primarily unchanged; however, many participant responses drew attention to perceived weaknesses of the standards. Details for each category are described below. 


\section{Overall Program/Therapy Effectiveness}

When asked if students who needed therapy services received them, 47.06\% (40/85) indicated that they disagreed or strongly disagreed. When asked if students with language impairment fulfilled IEP goals for the year, 44.83\% (39/87) responded that they agreed or strongly agreed. A total of $88.37 \%(76 / 86)$ indicated that they disagreed or strongly disagreed when asked if students with language impairment receiving speech and language services reached the grade-level of their same-aged peers. When asked if student outcomes changed since the implementation of the CCSS, 48.19\% (40/83) indicated that they disagreed or strongly disagreed. When asked how outcomes had changed since implementation of the CCSS, 60.71\% (51/84) responded that outcomes were unchanged. A total of $64.71 \%(55 / 85)$ indicated that the CCSS did not adequately address special needs students.

When asked their perception of their students' motivation to meet IEP goals, $78.57 \%(66 / 84)$ indicated students were slightly or moderately motivated. When asked how prepared they believed students were to master CCSS, 76.19\% (64/84) indicated students were slightly to moderately prepared. A total of $80 \%(68 / 85)$ of participants reported that students with language-impairment were, from an academic standpoint, moderately distant or very distant from their same-aged peers before therapy, while $78.31 \%$ $(65 / 83)$ reported that students with language-impairment were slightly or moderately distant from their same-aged peers after therapy.

Weaknesses of Standards

\begin{tabular}{|l|l|}
\hline \multicolumn{1}{|c|}{$\begin{array}{c}\text { Weakness-related segments } \\
\text { (44 segments total) }\end{array}$} & Description \\
\hline $\begin{array}{l}\text { Disregard of continuum of students } \\
\text { (34/44 weakness-related segments) }\end{array}$ & $\begin{array}{l}\text { Lack of consideration towards diverse students who are not on the same academic level as their same- } \\
\text { aged peers. }\end{array}$ \\
\hline $\begin{array}{l}\text { Developmentally inappropriate } \\
\text { standards (7/44 weakness-related } \\
\text { segments) }\end{array}$ & $\begin{array}{l}\text { Common Core Standards considered unrealistically advanced for the corresponding grade-level of } \\
\text { students. }\end{array}$ \\
\hline $\begin{array}{l}\text { Preference to measure students' own } \\
\text { progress }(3 / 44 \text { weakness-related } \\
\text { segments) }\end{array}$ & $\begin{array}{l}\text { Success of students with communicative disorders should not be measured by standards, but by their } \\
\text { own progress throughout the school year. }\end{array}$ \\
\hline
\end{tabular}

Table 5. Weakness-related segments.

Forty-four participant open-ended responses were coded as statements regarding the weaknesses found in the CCSS. These fell into three categories: disregard of continuum of students (34/44), developmentally inappropriate standards $(7 / 44)$ and preference to measure students' own progress (3/44).

Disregard of continuum of students (34/44 weakness-related segments) referred to participants who indicated that the CCSS do not take into account the diversity of students who are not on the same academic level as their same-aged peers. Developmentally inappropriate standards (7/44 weakness-related standards) referred to the CCSS being unrealistically advanced for the corresponding grade-level of students. Preference to measure students' own progress (3/44 weakness-related segments) was the code assigned to participants who believed the success of students with communicative disorders should not be measured by standards, but by their own progress throughout the school year.

Positive Aspects of Standards

\begin{tabular}{|c|c|}
\hline $\begin{array}{c}\text { Positive-related segments } \\
(2 \text { segments total) }\end{array}$ & Description \\
\hline $\begin{array}{l}\text { Differentiated instruction }(2 / 2 \text { positive- } \\
\text { related segments) }\end{array}$ & Opportunity for school staff to learn how to address diverse learners. \\
\hline \multicolumn{2}{|c|}{ Table 6. Positive-related segments. } \\
\hline
\end{tabular}

Table 6. Positive-related segments.

Two participant open-ended responses were coded as statements that indicated a positive aspect of the CCSS. These responses fell into a single category, differentiated instruction education (2/2). Differentiated instruction education $(2 / 2$ positive-related segments) referred to the opportunity for school staff to learn how to address diverse learners.

\section{Workload}

Participant responses regarding the CCSS' effect on workload fell into two categories: negative effects and type of approach. Insufficient amounts of time was the most cited difficulty. Most participants indicated a preference to a workload approach. Details of each category are specified below. 
A total of $29.89 \%(26 / 87)$ of participants indicated that the number of assessment referrals increased after implementation of the CCSS. When asked if there was a change in overall caseload after implementation of the CCSS, 65.88\% (56/85) indicated that caseload remained the same, however, $23.53 \%$ (20/85) indicated that there was an increase.

\section{Negative Effects}

A total of $79.52 \%(66 / 83)$ of participants either agreed or strongly agreed when asked if workload impacted service delivery. A majority, 86.36\% (57/66) reported a negative impact on service delivery, while $4.55 \%(3 / 66)$ reported a positive impact.

\begin{tabular}{|c|c|}
\hline $\begin{array}{l}\text { Negative effect-related segments } \\
\text { (117 segments total) }\end{array}$ & Description \\
\hline $\begin{array}{l}\text { Time restraints }(50 / 117 \text { negative effect- } \\
\text { related segments) }\end{array}$ & Inadequate amount of time provided for workload. \\
\hline $\begin{array}{l}\text { Understaffed schools }(29 / 117 \text { negative- } \\
\text { effect related segments) }\end{array}$ & $\begin{array}{l}\text { Disproportionately large workload compared to the number of Speech-Language Pathologists } \\
\text { employed in a given school. }\end{array}$ \\
\hline $\begin{array}{l}\text { Non-student related tasks }(20 / 117 \\
\text { negative effect-related segments) }\end{array}$ & $\begin{array}{l}\text { Participant responsibilities not directly related to working with students with communicative } \\
\text { disorders. } \\
\text { Note: Within this category, specific mention was made of paperwork }(17 / 20) \text { and meetings }(6 / 20) \text {. }\end{array}$ \\
\hline $\begin{array}{l}\text { SLP profession not understood }(12 / 117 \\
\text { negative effect-related segments) }\end{array}$ & $\begin{array}{l}\text { Necessary to explain the role and importance of an SLP in the academic success of children with } \\
\text { communicative disorders. }\end{array}$ \\
\hline $\begin{array}{l}\text { Personal time used }(5 / 117 \text { negative- } \\
\text { effect related segments) }\end{array}$ & Completion of job-related tasks during non-work hours. \\
\hline $\begin{array}{l}\text { Fewer referrals }(1 / 117 \text { negative-effect } \\
\text { related segments) }\end{array}$ & Decrease in speech/language referrals after the implementation of the CCSS. \\
\hline
\end{tabular}

Table 7. Negative effect-related segments.

One hundred seventeen participant open-ended responses were coded as statements regarding the negative workload effects of the CCSS. They fell into six categories: time restraints (50/117), understaffed schools (29/117), non-student related tasks (20/117), SLP profession not understood (12/117), personal time used (5/117) and fewer referrals (1/117).

Time restraints (50/117 negative effect-related segments) was the code that arose from responses that indicated a lack of time for the amount of work that needed to be completed. Understaffed schools (29/117 negative-effect related segments) referred to a disproportionately large workload compared to the number of Speech-Language Pathologists employed. Non-student related tasks (20/117 negative effect-related segments) referred to participant's responsibilities that were not directly related to working with communicatively disordered students. Within this category, specific mention was made of paperwork (17/20) and meetings (6/20). SLP profession not understood (12/117 negative effect-related segments) was the category that arose from participant responses that described having to explain the role and importance of an SLP in the academic success of children with communication disorders. Personal time used (5/117 negative-effect related segments) referred to participants who completed job-related tasks during their non-work hours. Fewer referrals $(1 / 117$ negative-effect related segments) was assigned to responses that indicated a decrease in referrals after the implementation of the CCSS.

Type of Approach

\begin{tabular}{|l|c|}
\hline \multicolumn{1}{|c|}{$\begin{array}{c}\text { Type of approach-related segments } \\
\text { (8 segments total) }\end{array}$} & Description \\
\hline $\begin{array}{l}\text { Caseload approach (6/8 type of } \\
\text { approach-related segments) }\end{array}$ & Administrations that consider the number of clients SLPs treat for speech and language services. \\
$\begin{array}{l}\text { Workload approach (2/8 approach- } \\
\text { related segments) }\end{array}$ & $\begin{array}{l}\text { Administrations that consider both number of clients seen and responsibilities outside of therapy, } \\
\text { including meetings, paperwork and professional development. }\end{array}$ \\
\hline
\end{tabular}

Only open-ended questions were used to determine the type of caseload/workload approach used in schools. Eight participant open-ended responses were coded as descriptions of the type of approach used within their district, which fell into two distinct categories/themes: caseload approach (6/8) and workload approach (2/8).

Caseload approach (6/8 type of approach-related segments) referred to administrations who consider the number of clients SLPs treat for speech and language services, while the workload approach (2/8 type of approach-related segments) referred to administrations who took into account both clients seen and responsibilities outside of therapy, including meetings, paperwork and professional development. 


\section{Continuing Education}

Major themes for continuing education fell into two categories: Need for training and the type of training in which participants engaged. Most participants reported needing more training to familiarize themselves with the CCSS. The training in which they reported engaging included self-directed learning, district/administration led training, teacher training/resources, ASHA training/resources and general online resources among others. The details for each of these categories follow.

\section{Need for training}

A total of $98.84 \%$ of participants (85/86) reported being at least somewhat familiar with the Common Core State Standards (CCSS). Yet, far fewer, 61.63\% (53/86), reported being somewhat or very familiar with the Application to Students with Disabilities document. ${ }^{8}$ Overall, $82.14 \%$ (69/84) of participants somewhat or strongly agreed that more training, similar to teacher continuing education focused on implementation of CCSS into curriculum, is necessary. However, 67.57\% (25/37) of participants agreed that the time spent on CCSS training compromises time planning therapy sessions. A total of $88.89 \%(72 / 81)$ of participants indicated that time spent familiarizing with the CCSS was moderately or very time consuming.

Twenty-four participant open-ended responses were coded as statements regarding the nature of the type of additional training needed. These fell into nine categories: general conferences and workshops (7/24), online learning opportunities (4/24), training geared specifically toward SLPs (3/24), school district-specific training (2/24), training in collaboration with teachers $(2 / 24)$, mentorship from more experienced SLPs (2/24), American Speech-Language-Hearing Association led training (2/24), training specifically on how to apply CCSS to students with disabilities $(1 / 24)$ and training for administrators $(1 / 24)$. Categories for type of training needed are self-explanatory. Table/definitions are not provided for this section.

Type of training used

\begin{tabular}{|c|c|}
\hline $\begin{array}{l}\text { Type of training-related segments } \\
\text { (138 segments total) }\end{array}$ & Description \\
\hline $\begin{array}{l}\text { Self- directed learning }(45 / 138 \text { type of } \\
\text { training-related segments) }\end{array}$ & $\begin{array}{l}\text { Self-familiarization of Common Core Standards. } \\
\text { Note: Of the } 45 \text { total codes in the self-directed learning category, specific reference was made to the } \\
\text { "Common Core Standards" App by MasteryConnect (10/45), as well as self-direction by simply } \\
\text { reading through the standards (10/45). All other responses were coded as unspecified self-directed } \\
\text { learning. }\end{array}$ \\
\hline $\begin{array}{l}\text { District/administration-led training } \\
\text { ( } 34 / 138 \text { type of training-related } \\
\text { segments) }\end{array}$ & $\begin{array}{l}\text { Formal SLP training provided by school districts and administrators. } \\
\text { Note: Reference to Boards of Cooperative Educational Services (BOCES) Programming }(1 / 34) \text { and } \\
\text { Professional Learning Community (PLC) implementation (1/34) were mentioned in the } \\
\text { district/administration-led training. }\end{array}$ \\
\hline $\begin{array}{l}\text { ASHA trainings/resources }(12 / 138 \\
\text { type of training-related segments) }\end{array}$ & $\begin{array}{l}\text { Resources and trainings provided by ASHA. } \\
\text { Note: Of the } 12 \text { codes in the ASHA trainings/resources category, specific reference was made to } \\
\text { guidance in the form of course offerings and workshops }(5 / 12) \text {, ASHA convention workshops } \\
\text { ( } 2 / 12) \text {, ASHA's public school conferences }(2 / 12) \text {, general/unspecified ASHA resources }(2 / 12) \text {, and } \\
\text { Continuing Education Units }(1 / 12) \text {. }\end{array}$ \\
\hline $\begin{array}{l}\text { Online resources }(12 / 138 \text { type of } \\
\text { training-related segments) }\end{array}$ & $\begin{array}{l}\text { Use of web-based resources to familiarize with the CCSS. } \\
\text { Note: The online resources category consisted of online research }(6 / 12) \text { and online training }(6 / 12) \text {. } \\
\text { The online research category }(6 / 12) \text { referred to resources such as articles and blogs, while online } \\
\text { training }(6 / 12) \text { was reserved for participants who used some form of web-based training to } \\
\text { familiarize with the CCSS. }\end{array}$ \\
\hline $\begin{array}{l}\text { Collaboration as a means to } \\
\text { familiarization with the CCSS }(10 / 138 \\
\text { type of training-related segments) }\end{array}$ & SLPs working with teachers to familiarize with the CCSS. \\
\hline $\begin{array}{l}\text { SLP-specific training }(9 / 138 \text { type of } \\
\text { training-related segments) }\end{array}$ & $\begin{array}{l}\text { Trainings geared directly towards SLPs for incorporation of the Common Core standards into } \\
\text { therapy sessions. }\end{array}$ \\
\hline $\begin{array}{l}\text { Teacher training/ resources }(7 / 138 \\
\text { type of training-related segments })\end{array}$ & $\begin{array}{l}\text { Trainings or resources used by SLPs created specifically for classroom teachers. } \\
\text { Note: Specific reference to the Teachers Pay Teachers website (bttps:/ / wnw.teacherspayteachers.com) was } \\
\text { made in the teacher trainings/resources category }(5 / 7) \text {. The other codes in the category }(2 / 7) \text { did not } \\
\text { identify a specific resource. }\end{array}$ \\
\hline $\begin{array}{l}\text { Unspecified training category }(6 / 138 \\
\text { type of training-related segments) }\end{array}$ & No specific indication of type of training used. \\
\hline $\begin{array}{l}\text { Name-specific resources }(3 / 138 \text { type of } \\
\text { training-related segments) }\end{array}$ & Inclusion of distinct names of individuals who have helped in the education of the CCSS. \\
\hline
\end{tabular}


Only open-ended questions were used to determine the type of training used to familiarize oneself with the CCSS. Analysis of narrative responses resulted in 138 type of training-related segments. The resultant segments included nine categories of reported resources used: self-directed learning (45/138), district/administration-led training (34/138), American Speech-Language-Hearing Association (ASHA) trainings/resources (12/138), online resources (12/138), collaboration as a means to familiarization with the CCSS (10/138), SLP-specific training (9/138), teacher trainings/resources (7/138), unspecified training (6/138) and name-specific resources $(3 / 138)$.

The self- directed learning category (45/138 type of training-related codes) referred to participant remarks that indicated selffamiliarization with the standards. Of the 45 total codes in the self-directed learning category, specific reference was made to the "Common Core Standards" App by MasteryConnect (10/45), as well as self-direction by simply reading through the standards (10/45). All other responses were coded as unspecified self-directed learning; for instance, one participant simply reported, "selffamiliarization". The district/administration-led training (34/138 type of training-related codes) category referred to formal training that school districts and administrators provided to the SLPs. Reference to Boards of Cooperative Educational Services (BOCES) Programming (1/34) and Professional Learning Community (PLC) implementation (1/34) were mentioned in the district/administration-led training. ASHA trainings/resources (12/138 type of training-related codes) referred to guidance in the form of course offerings and workshops (5/12), ASHA convention workshops (2/12), ASHA's public school conferences (2/12), general/unspecified ASHA resources (2/12), and Continuing Education Units (1/12). The online resources (12/138 type of training-related codes) code referred to participant responses that indicated use of web-based resources to familiarize with the CCSS. The online resources category consisted of online research (6/12) and online training (6/12). The online research category $(6 / 12)$ referred to resources such as articles and blogs, while online training $(6 / 12)$ was used for participants who used some form of web-based training to become familiar with the CCSS. Collaboration as a means to familiarization with the CCSS (10/138 type of training-related codes) was assigned to participants who reported working together with teachers to familiarize themselves with the CCSS. SLP-specific training (9/138 type of training-related codes) referred to trainings geared directly towards SLPs for incorporating the CCSS into therapy sessions. Teacher training/ resources (7/138 type of training-related codes) were trainings or resources used by SLPs that were created specifically for classroom teachers. Specific reference to the Teachers Pay Teachers website (bttps:// www.teacherspayteachers.com) was made in the teacher trainings/resources category (5/7). The other codes in the category $(2 / 7)$ did not identify a specific resource. The unspecified training category (6/138 type of training-related codes) indicated that participants received some form of training, but did not detail the type. The name-specific resources category (3/138 type of training-related codes) included distinct names of individuals who have helped in the education of the CCSS.

\section{DISCUSSION}

\section{CCSS'Perceived Impact on Service Delivery}

In terms of the participant SLPs' perception of the CCSS' impact on delivery of speech/language services, most (86.05\%) SLPs reported incorporating the CCSS into speech-language sessions. However, less than half indicated that incorporating the standards was an easy task. Despite the perceived difficulty incorporating the standards, over half of the SLPs reported that the standards were at least somewhat helpful in the facilitation of the generalization of skills.

Around half of the SLPs also reported that time in therapy, class time, time for generalization of skills, as well as assistive technology were resource needs that were only somewhat met since implementation of the CCSS.

It was apparent from the data that school-based SLPs often collaborate with a range of other professionals. The most frequently cited strategy for successful collaboration with teachers was rapport building. For example, participants reported the need to develop both respect and friendship with teachers in order to maximize interprofessional collaborations. Further, participants also reported that collaboration may take the form of the SLP adapting to the teachers' lesson plans versus asking the teacher to adapt to the SLP's needs.

The participant SLPs reported that group sizes, for most, did not change as a result of the CCSS. However, there were some participants who reported fewer small-to-moderate group sizes after implementation of the CCSS as well as some who reported that number of group sessions increased after the implementation of the CCSS. These changes in group size and group session frequency were only reported by a minority of participants. This variability highlights differences across practice settings and suggests that it is unlikely that a "common" effect on service delivery will be experienced across the U.S. Along the lines of implementation variability, the participants reported direct implementation of the CCSS into speech-language sessions while others reported more indirect methods. Again, a "common" experience across participants was not reported and it appeared that individual SLPs varied in how much difficulty was reported in implementing the standards into sessions. Interestingly, a small minority of participants reported that implementation of the standards into speech-language sessions has decreased the quality of services. 


\section{CCSS'Perceived Impact on Student Outcomes}

Despite some participant reports of a decrease in speech-language service quality as a result of the CCSS, more than half of those surveyed reported that there was no change in student therapy outcomes as a result of the CCSS. At the same time, over half also reported that the CCSS do not adequately address special needs students. The CCSS' perceived lack of application to special needs students may explain the perceived lack of change in student speech-language outcomes after CCSS implementation.

Along those lines, a theme based on the weaknesses of the CCSS emerged from open-ended responses to the survey questions. Specifically, some SLPs reported that the CCSS disregard a continuum in student ability. Others reported that the standards are developmentally inappropriate. These perceptions mirror those of critics of the CCSS. 5,6

Far fewer positive aspects of the CCSS arose from the participant open-ended response. Only two segments were identified which indicated support for the CCSS. Specifically, both of those segments highlighted how the implementation of the CCSS has added to staff education in terms of recognizing how to better address diverse learners. Identified weaknesses were far more robust in terms of the number of mentions in the dataset.

\section{CCSS'Perceived Impact on Workload}

Similar to the greater number of CCSS weaknesses versus strengths that the participants reported, workload was largely perceived to be negatively affected by the implementation of the CCSS. Workload for about a quarter of the participants was reported to have increased as a result of CCSS implementation. At the same time, over half of the participants reported that caseload had not changed since implementation of the CCSS.

Despite the largely unchanged caseload, almost $80 \%$ of the participants agreed that their overall workload was impacting service delivery. Over $80 \%$ specified that the impact on service delivery was negative.

Inspection of the open-ended data specified that time restraints was the major negative impact of the CCSS. Specifically, increased referrals coupled with understaffed schools and time spent on non-therapy tasks negatively affected the quality of speech-language services.

A small number of participants expressed frustration in the manner in which school districts measured productivity. For example, those SLPs reported that a workload approach would more adequately address the time issues that arose from the data.

\section{CCSS' Perceived Impact on Continuing Education}

A majority of participants indicated a desire for more training in order to properly implement the CCSS into speech and language services. Most participants indicated that time spent becoming familiar with the CCSS compromised time spent planning therapy sessions, which was possibly due to a lack of structured training. The most cited response to need for training was a need for more general conferences and workshops, followed by a need for online learning opportunities and need for training geared specifically toward SLPs. Most participants indicated that their current means of familiarizing themselves with the CCSS was through self-directed learning, and some indicated that they received district/administration-led training, although it was not always geared specifically to the role of the SLP. Other means of familiarization included ASHA trainings/resources and online resources. Many participants reported use of more than one approach to familiarize themselves with the CCSS. It is apparent from this research that continuing education/training specific to SLPs' implementation of the CCSS into speech-language therapy is needed. Based on these participants' self-directed learning efforts, online learning could be used to reach the most professionals in the most cost efficient and time-sensitive manner.

\section{CONCLUSIONS}

Major Outcomes and Significance

Prior to the completion of this study, we found no research regarding the effect of the CCSS on speech-language services in schools. Our survey highlighted four areas-service delivery, student outcomes, professional workload and continuing professional education. Negative aspects of the CCSS far exceeded positive aspects reported by participants, specifically through open ended questions. Many SLPs cited difficulties with implementation, much of which stemmed from time restraints and variability in implementation methods. Although a heavy majority of SLPs incorporated standards into therapy, some reported loosely using the standards as a guide, while others outlined direct methods of aligning standards to therapy goals. Closed-ended responses, many of which asked participants to compare student outcomes before and after CCSS, revealed that student outcomes after implementation of the CCSS remained primarily unchanged. Although student outcomes were comparable, there was a reported increase in workload responsibilities that negatively impacted speech-language services. Time restraints and paperwork were both cited as sources that compromised planning time for therapy. Many participants indicated familiarization of standards through self-direction and reported a need for additional training to aid in uniform implementation of CCSS into therapy. Our findings call for more communication in how CCSS are implemented across states to identify individual differences between states' efforts and additional training geared specifically to SLPs to increase the likelihood of effective incorporation of the CCSS into therapy. 


\section{Limitations}

The current study aimed to gather perceptions of the CCSS across the U.S.; however, not every state was represented in the survey responses. The survey had a relatively small sample size of 106, which was reduced to roughly 87 after participants from non-CCSS states were subtracted from the total number of participants. There are approximately 72,359 ASHA-certified SLPs working in school settings across the U.S. ${ }^{9}$ The sample of 87 respondents represents $0.1 \%$ of the total population working in schools. All respondents were female and a majority was over the age of 40 . The invitation to complete the survey was only posted on three American Speech-Language-Hearing Association online communities and participants were self-selected, limiting the diversity of respondents to those who are active on the various online communities. While the results of the survey are helpful in understanding SLPs' perceptions of the CCSS, the strengths and weaknesses of the CCSS for children receiving speechlanguage services, and the ongoing training needs in educational settings, these results may not be representative of the schoolbased SLP population at large.

Future Studies

Workload concerns emerged as one of the most prominent barriers identified in the workplace. More research into how administrative support effects the perceived workplace satisfaction in light of the new standards is one possible area to be investigated. The focus can also be turned to ways administration can ease workload impact to promote the most effective speech and language services. In addition, a future study could compare workload and caseload approaches to measure both the job satisfaction and student outcomes that result.

Another area open to investigation is the collaborative relationships between SLPs and teachers. Collaboration was a subsection of the service delivery portion of this study, but can be investigated in much more depth. It would be interesting to consider the perceptions of both SLPs and classroom teachers in their support for collaboration and perception of importance to students with communicative disorders.

\section{ACKNOWLEDGMENT}

The authors thank the St. John's University's Graduate Admission Assistance Program for the funding of the research reported in this article.

\section{REFERENCES}

1. National Governors Association Center for Best Practices, Council of Chief State School Officers. (2010a) About the Standards. Washington, DC: National Governors Association for Best Practices, Council of Chief State School Officers. Retrieved from http:// www.corestandards.org/about-the-standards/

2. Staskowski, M. (2012) Overview of the common core state standard initiative and educational reform movement from the vantage of speech-language pathologists. Semin Speech Lang, 33(02), 095-101. doi: 10.1055/s-0032-1310310

3. Power-deFur, L. A. (2016) Common Core State Standards and the speech-language pathologist: Standards-based intervention for special populations. San Diego, CA: Plural Publishing.

4. McLaughlin, M., and Overturf, B. J. (2012) The common core: Insights into the K-5 standards. The Reading Teacher, 66(2), 153164. doi: $10.1002 / \operatorname{trtr} .01115$

5. VanTassel-Baska, J. (2015) Arguments for and against the common core state standards. Gifted Child Today, 38(1), 60-62. doi: $10.1177 / 1076217514556535$

6. Doyle, K. (2012) Powerful alignment: Building consensus around the common core state standards. Language and Literacy Spectrum, 22, 7-23.

7. American Speech-Language-Hearing Association (n.d.) Common Core State Standards: A resource for SLPs. Retrieved May 1, 2016, from http:/ / wmw.asha.org/SLP/schools/Common-Core-State-Standards/

8. National Governors Association Center for Best Practices, Council of Chief State School Officers. (2010b) Application to Students with Disabilities. Washington, DC: National Governors Association for Best Practices, Council of Chief State School Officers. Retrieved from http://www.corestandards.org/wp-content/uploads/Application-to-Students-with-Disabilities-again-for-merge1.pdf

9. American Speech-Language-Hearing Association. (2017). ASHA summary membership and affiliation counts, year-end 2016. Available from www.asha.org.

10. Creswell, J. W. (2004) Educational research: Planning, conducting, and evaluating quantitative and qualitative research, $2^{\text {nd }}$ ed. Upper Saddle River, NJ: Prentice Hall.

11. Miles, M.B., and Huberman, A.M. (1994) Qualitative research analysis, $2^{\text {nd }}$ ed. Thousand Oaks, CA: Sage Publications. 


\section{ABOUT THE STUDENT AUTHOR}

Nicole Ariza is a recent graduate of St. John's University. She majored in Speech-Language Pathology and Audiology and minored in Spanish. With a special interest in bilingualism and professional issues in Speech-Language Pathology, she looks forward to completing her graduate studies at St. John's University in Spring 2018.

\section{PRESS SUMMARY}

The implementation of the Common Core State Standards has been received with a combination of both support and opposition. The current study aimed to gather insight from the perspective of school-based Speech-Language Pathologists (SLPs) across the United States to measure the CCSS' impact within the profession. Results indicated that student outcomes have remained consistent before and after implementation, however, workload has heavily increased. Results also showed that there may be flaws and inconsistencies in the implementation of the standards, making it difficult for SLPs to properly incorporate the standards into therapy. The results indicated a need for continued professional education on the subject matter. 